\title{
Glucocorticoid receptor overexpression slightly shifts microRNA expression patterns in triple-negative breast cancer
}

\author{
DOMINIK BUSCHMANN ${ }^{1,2 *}$, RICARDO GONZÁLEZ ${ }^{1,3^{*}}$, BENEDIKT KIRCHNER $^{2}$, CLAUDIA MAZZONE $^{4}$, \\ MICHAEL W. PFAFFL ${ }^{2}$, GUSTAV SCHELLING ${ }^{5}$, ORTRUD STEINLEIN ${ }^{1}$ and MARLENE REITHMAIR ${ }^{1}$ \\ ${ }^{1}$ Institute of Human Genetics, University Hospital, LMU Munich, 80336 Munich; ${ }^{2}$ Division of Animal Physiology \\ and Immunology, TUM School of Life Sciences Weihenstephan, Technical University of Munich, \\ 85354 Freising, Germany; ${ }^{3}$ Faculty of Sciences, University of Porto, 4169-007 Porto, Portugal; \\ ${ }^{4}$ Department of Pharmacy and Medicine, Sapienza University of Rome, 00185 Rome, Italy; \\ ${ }^{5}$ Department of Anesthesiology, University Hospital, LMU Munich, 81377 Munich, Germany
}

Received December 15, 2017; Accepted February 15, 2018

DOI: $10.3892 /$ ijo.2018.4336

\begin{abstract}
Triple-negative breast cancer (TNBC) is a particularly aggressive subtype of breast cancer with limited options for clinical intervention. As with many solid tumors, TNBC is known to promote invasiveness and metastasis by secreting extracellular vesicles (EVs) capable of modulating the behaviour of recipient cells. Recent investigations have demonstrated that high expression levels of glucocorticoid receptor (GR) in TNBC are linked to therapy resistance, higher recurrence rates and increased mortality. In addition to activating protein-coding genes, GR is also involved in the expression of short non-coding RNAs including microRNAs (miRNAs or miRs). The molecular mechanisms responsible for the oncogenic effects of GR on TNBC have yet to be fully elucidated; however, emerging evidence suggests that miRNAs may play a pivotal role in tumorigenesis and metastasis. Thus, the aim of this study was to identify GR-regulated cellular and vesicular miRNAs that might contribute to the particularly oncogenic phenotype of TNBC with a high GR expression. We analyzed miRNA profiles of three TNBC cell lines using an in vitro model of GR overexpression. Next-generation sequencing revealed minor, cell line-specific changes in cellular miRNA expression, whereas vesicular miRNAs were not significantly regulated by GR. Additionally, the analysis of predicted miRNA targets failed to establish a causal link between GR-induced miRNA expression and oncogenic signaling. On
\end{abstract}

Correspondence to: Mr. Dominik Buschmann, Division of Animal Physiology and Immunology, TUM School of Life Sciences Weihenstephan, Technical University of Munich, Weihenstephaner Berg 3, 85354 Freising, Germany

E-mail: dominik.buschmann@wzw.tum.de

${ }^{*}$ Contributed equally

Key words: triple-negative breast cancer, glucocorticoid receptor, microRNA, miR-203a-3p, MDA-MB-436, MYLK, exosome the whole, given that GR influences miRNA profiles to only a small degree, other mechanisms are more likely to be responsible for the increased mortality of patients with TNBC with a high GR expression.

\section{Introduction}

Breast cancer (BC) is the most prevalent type of cancer affecting women, and the second most common type of cancer as a whole. Globally, the incidence of BC is one in nine women (1). Despite substantial advancements in diagnosis and treatment, the mortality rates for BC are still at $15 \%$ (2).

One of the most aggressive variants of $\mathrm{BC}$ is triple-negative BC (TNBC). This subgroup of BC cells does not express the receptors for estrogen (ER), progesterone receptor (PR) and human epidermal growth factor 2 (HER2). The absence of these proteins renders commonly used clinical interventions, such as inhibiting aromatase and blocking hormone receptors ineffectual for TNBC therapy $(3,4)$. Treatment is therefore limited to surgical resection and adjuvant chemotherapy, making TNBC a significant unmet clinical need (5).

Synthetic glucocorticoids, such as dexamethasone are commonly used in tumor therapy (6). However, recent data have indicated that mortality is increased in patients with TNBC variants overexpressing glucocorticoid receptor (GR). GR signaling activates oncogenes, inhibits apoptosis and represses tumor suppressor genes in TNBC, leading to unfavorable clinical outcomes (7). A high GR expression is also associated with therapy resistance and increased recurrence (8).

In addition to regulating protein-coding genes, GR is known to activate non-coding RNAs, including microRNAs (miRNAs or miRs) (9). These molecules of 18-22 nt in length modulate cellular gene expression by specifically binding complementary mRNA sequences and repressing their translation. Highly malignant tumor cells commonly display dysregulated miRNA profiles, leading to oncogenic and anti-apoptotic signaling (10). For TNBC, previous studies have discovered signatures of altered miRNA expression that distinguish cancer cells from surrounding tissues, and predict the receptor status for ER, PR and HER2 $(11,12)$. Additionally, 
the analysis of miRNAs highlights the heterogeneity of TNBC phenotypes and their respective signaling pathways (13). Unraveling miRNA regulation for individual TNBC variants is therefore crucial to understand pathogenesis and draw consequences about potential therapeutic interventions.

Recent studies have indicated that TNBC modulates distant cells by secreting signaling factors, including extracellular vesicles (EVs). EVs shed from tumor cells are enriched in specific miRNAs that might contribute to tumor progression and metastasis (14). Indeed, BC EVs have been found to induce the proliferation, migration and invasion of recipient cells, thus enhancing disease progression (15-17). Exploiting circulating miRNAs for the diagnosis and prognosis of TNBC patients might yield powerful biomarkers that are easily accessible via liquid biopsy (18).

To the best of our knowledge, however, to date, there is no study available investigating the effects of GR signaling on miRNA regulation in TNBC. Thus, in this study, to address this knowledge gap, we analyzed cellular and vesicular miRNA profiles in an in vitro model of GR-overexpressing TNBC by high-throughput next-generation sequencing (NGS). Surprisingly, no statistically significant alterations in EV miRNAs were detected in two TNBC cell lines upon GR overexpression. We did, however, detect a small set of cellular miRNAs regulated by GR in a cell line-specific manner. As the validation of miRNA target genes yielded ambiguous results, we concluded that the unfavorable influence of a high GR expression on TNBC phenotypes is not mediated by miRNAs to a significant extent.

\section{Materials and methods}

TNBC cell culture and transfection. The human TNBC cell lines, MDA-MB-231, MDA-MB-436 and MDA-MB-468, were purchased from the Leibnitz Institute DSMZ-German Collection of Microorganisms and Cell Culture (Braunschweig, Germany) and Cell line services (Eppelheim, Germany).

The cells were cultured in T75 flasks in a monolayer in DMEM (Sigma-Aldrich, Hamburg, Germany) containing $4.5 \mathrm{~g} / 1$ glucose, $1 \%$ L-glutamine, $10 \%$ exosome-depleted fetal bovine serum (FBS) (BioCat GmbH, Heidelberg, Germany), $160 \mathrm{ng} / \mathrm{l}$ cortisol and 1\% penicillin/streptomycin (Invitrogen, Karlsruhe, Germany). Cultures were maintained in a humidified atmosphere at $37^{\circ} \mathrm{C}$ and $5 \% \mathrm{CO}_{2}$. For the experiments studying cellular miRNAs, the MDA-MB-231, MDA-MB-436 and MDA-MB-468 cells were seeded $4.5 \mathrm{~h}$ prior to transfection at a concentration of $1 \times 10^{5}$ cells per well in 24 -well plates (Greiner Bio-One, Frickenhausen, Germany) using $0.5 \mathrm{ml}$ culture medium.

GR overexpression was induced by transfecting the TNBC cells with nuclear receptor subfamily 3 group $C$ member 1 (NR3C1)-encoding DNA plasmids. The coding sequence (CCDS4278.1) of the predominant glucocorticoid receptor gene $N R 3 C 1$ transcript variant 1 (NM_000176.2) was synthesized with the restriction sites $K p n I$ and XhoI on the $5^{\prime}$ and 3 ' end, respectively (MWG Eurofins, Ebersberg, Germany), and cloned in frame into the pcDNA6/V5-His A vector (Life Technologies, Darmstadt, Germany). The cells were transfected with the NR3C1 plasmid $(0.4 \mu \mathrm{g})$ for $24 \mathrm{~h}$ using Lipofectamine 2000 transfection reagent (Invitrogen).
Following $30 \mathrm{~h}$ of cultivation, the cells had reached $90 \%$ confluency, and were rinsed once with HBSS before proceeding to total RNA extraction.

For experiments studying EV miRNAs, the MDA-MB-231 and MDA-MB-468 cells were seeded at a concentration of $3 \times 10^{6}$ cells per well in 6-well plates (Greiner Bio-One). Both parental and transfected cells were seeded in 3 wells with $2.5 \mathrm{ml}$ culturing medium each. Transfection was performed with $2.5 \mu \mathrm{g}$ of plasmid harboring the coding sequence of NR3C1.

For all experiments, untransfected cells with endogenous GR expression were used as control samples. Three independent technical replicates per cell line were analyzed.

Validation of NR3Cl overexpression. To evaluate the effectiveness of transfection, the NR3Cl mRNA levels were quantified by reverse transcription-quantitative (real-time) PCR (RT-qPCR). Total RNA from each cell line was initially reverse transcribed using the QuantiTect Reverse Transcription kit (Qiagen, Hilden, Germany) according to the manufacturer's instructions. Quantitative PCR was performed using the Prime PCR Assay NR3C1 and GAPDH human SsoAdvanced universal supermix (Bio-Rad, Munich, Germany) and $10 \mathrm{ng}$ of template cDNA. PCR reactions were run on a MiniOpticon real-time PCR system (Bio-Rad). Additionally, the transcription levels of NR3C1 downstream targets dual specificity phosphatase 1 (DUSP1; NM_004417), serum/glucocorticoid regulated kinase 1 (SGK1; NM_005627.3) and glucocorticoidinduced leucine zipper protein (GILZ; NM_198057.2) were assessed by RT-qPCR. For each cell line, total RNA from three biological replicates was reverse transcribed using the QuantiTect Reverse Transcription kit (Qiagen). Subsequently, $8 \mathrm{ng}$ cDNA were analyzed in a $10 \mu \mathrm{l}$ reaction volume of SsoFast EvaGreen Supermix (Bio-Rad) and $300 \mathrm{nM}$ primers (Sigma-Aldrich). Real-time PCR was carried out on triplicate samples using a Rotor-Gene Q thermal cycler (Qiagen) and a thermal profile for polymerase activation $\left(95^{\circ} \mathrm{C}\right.$ for $\left.1 \mathrm{~min}\right)$ and 45 cycles of amplification $\left(95^{\circ} \mathrm{C}\right.$ for $10 \mathrm{sec} 60^{\circ} \mathrm{C}$ for $15 \mathrm{sec}, 65^{\circ} \mathrm{C}$ for $45 \mathrm{sec}$ ). The primer sequences are provided in Table I. The expression of $\mathrm{NR} 3 \mathrm{Cl}$ and its downstream targets was normalized to $G A P D H$, a stable reference gene for breast cancer cells (19). Relative quantification was carried out using the $\Delta \Delta \mathrm{Cq}$ method (20). Statistical significance was determined using the Student's t-test. Values of $\mathrm{P}<0.05$ were considered to indicate statistically significant differences.

Extracellular vesicle isolation and characterization. For EV isolation, $7.5 \mathrm{ml}$ of cell culture supernatant were collected from the parental and transfected cells after $30 \mathrm{~h}$ of cultivation, and centrifuged (3,200 x g, $5 \mathrm{~min})$ to remove the cellular debris. EVs were isolated from pre-cleared supernatant using the miRCURY Exosome Isolation kit - Cells, urine and CSF according to the manufacturer's instructions (Exiqon, Vedbaek, Denmark). EV pellets were resuspended in either lysis buffer for RNA extraction, or PBS for vesicle characterization.

For nanoparticle tracking analysis (NTA), the EVs were diluted in particle-free PBS and analyzed on a NanoSight LM10 (Malvern Instruments GmbH, Herrenberg, Germany) using a $408 \mathrm{~nm}$ laser and NTA 3.0 software. Four videos of $30 \mathrm{sec}$ each were captured, and analyzed using default settings 
Table I. Primer pairs used for validation of $\mathrm{NR} 3 \mathrm{Cl}$ overexpression.

\begin{tabular}{lll}
\hline Name & \multicolumn{1}{c}{ Forward primer (5'-3') } & \multicolumn{1}{c}{ Reverse primer (5'-3') } \\
\hline DUSP1 & GCCATTGACTTCATAGACTCCATC & ATGATGCTTCGCCTCTGCTT \\
SGK1 & GACGGTGAAAACTGAGGCTG & AGAAGGACTTGGTGGAGGAGA \\
GILZ & TCTTCTTCCACAGTGCCTCC & TCTTCAGGGCTCAGACAGGA
\end{tabular}

DUSP1, dual specificity phosphatase 1; SGK1, serum/glucocorticoid-regulated kinase 1; GILZ, glucocorticoid-induced leucine zipper.

for blur and minimum track length, and a detection threshold of two.

RNA extraction and NGS library preparation. Total RNA was isolated from the cells and EVs using the miRCURY RNA Isolation kit - Cell and Plant (Exiqon,) according to the manufacturer's instructoins. Cellular RNA was quantified using a nanophotometer (Implen GmbH, Munich, Germany), and RNA integrity was assessed by capillary electrophoresis on the Bioanalyzer 2100 using the RNA 6000 Nano kit (Agilent Technologies, Waldbronn, Germany). EV RNA was analyzed using the Agilent Small RNA kit (Agilent Technologies).

Sequencing libraries were constructed from $190 \mathrm{ng}$ of cellular RNA, or the entire EV RNA isolated from $7.5 \mathrm{ml}$ conditioned culture medium, respectively. Library preparation was performed as previously described by Spornraft et al (21). Briefly, the RNA was adaptor-ligated, reverse-transcribed, amplified by PCR and barcoded using the NEBNext Multiplex Small RNA Library Prep Set for Illumina (New England BioLabs Inc., Frankfurt, Germany). Adaptors and primers were diluted 1:2 in nuclease-free water to accommodate the low RNA input. Size selection of pooled PCR products was performed by agarose gel electrophoresis (4\%), cutting out bands with 130 to $150 \mathrm{bp}$ fragments. The purity and concentration of the libraries extracted from the gel were verified by capillary electrophoresis using the High Sensitivity DNA kit on the Bioanalyzer 2100 (Agilent Technologies). Finally, the libraries were subjected to Illumina single-end sequencing-by-synthesis using 50 cycles on the HiSeq 2500 (Illumina Inc., San Diego, CA, USA).

Data processing and differential gene expression analysis. FastQC (version 0.11.5) was used to assess the sequence length distribution and quality of the NGS data, as previously described (22). Adaptor sequences were trimmed using BTRIM, and all reads without adaptors were discarded (23). Additionally, reads shorter than $15 \mathrm{nt}$ were excluded from the data set (24). Prior to miRNA analysis, reads pertaining to ribosomal RNA (rRNA), transfer RNA (tRNA), small nuclear RNA (snRNA) and small nucleolar RNA (snoRNA) were removed by mapping to sequences obtained from RNAcentral (25). The remaining reads were then aligned to miRBase (version 21) (26). Mapping was carried out using Bowtie and the 'best' alignment algorithm, allowing one mismatch for both RNAcentral and miRBase (27). Final read count tables were generated by sorting and indexing aligned reads using SAMtools, and calling the sum of hits per miRNA sequence (28). Differential gene expression analysis was subsequently performed via the bioconductor package DESeq2 (version 1.8.1), using the Benjamini-Hochberg method to correct for false discovery (29). A $\log 2$ fold change $\geq|1|$ and an adjusted p-value (Padj) of $\leq 0.05$ were set as thresholds to identify significantly regulated miRNAs. Only miRNAs with a mean expression of at least 50 counts were included in the analysis. Principal component analysis (regularized log-transformed, sizefactor-corrected counts obtained from DESeq2), and data visualization were performed in $\mathrm{R}$ (version 3.4.0) using the packages gplots, ggfortify, genefilter and RColorBrewer.

Validation of regulated miRNAs. Based on the NGS data, differentially regulated cellular miRNAs were validated by RT-qPCR. First, $111 \mathrm{ng}$ of RNA were reverse transcribed in triplicate using the miScript II RT kit (Qiagen) according to the manufacturer's instructions. A total of $1 \mu \mathrm{l}$ cDNA was subjected to real-time PCR in a $10 \mu 1$ reaction volume using the miScript SYBR-Green PCR kit (Qiagen). Reactions were run on a CFX384 real-time PCR detection system (Bio-Rad) using the recommended protocol of polymerase activation $\left(95^{\circ} \mathrm{C}\right.$ for $15 \mathrm{~min})$ and 45 cycles of amplification $\left(94^{\circ} \mathrm{C}\right.$ for $15 \mathrm{sec}$, $55^{\circ} \mathrm{C}$ for $30 \mathrm{sec}, 70^{\circ} \mathrm{C}$ for $\left.30 \mathrm{sec}\right)$. Quantification cycle $(\mathrm{Cq})$ values were determined automatically using default threshold settings, and $\mathrm{Cq}$ values above 37 were manually set to 40 . The NGS data was utilized to assess potential reference miRNAs using the geNorm and NormFinder algorithms $(30,31) . \mathrm{Cq}$ values of regulated miRNAs were subsequently normalized to the geometric mean of the following reference miRNAs: miR-24-3p, miR-25-3p and miR-148b-3p for MDA-MB-231 and MDA-MB-436, and miR-24-3p, miR-25-3p and let-7a-5p for MDA-MB-468. Relative quantification was carried out using the $\Delta \Delta \mathrm{Cq}$ method (20). Statistical significance was assessed using Student's t-test. Values of $\mathrm{P}<0.05$ were considered to indicate statistically significant differences.

Prediction and quantification of miRNA target genes. miRWalk 2.0 was used to predict mRNAs targeted by miR-203a-3p (32). Four target genes known to be associated with metastasis in solid tumors [Actin, gamma 2, smooth muscle, enteric (ACTG2), calponin 1 (CNN1), major histocompatibility complex, class II, DP beta 1 (HLA-DPBI) and myosin light chain kinase $(M Y L K)]$ were selected for analysis by RT-qPCR (33). The expression of these genes was quantified in the same cellular MDA-MB-436 samples previously used for NGS. Initially, RNA was reverse transcribed in triplicate using the QuantiTect Reverse Transcription kit (Qiagen) according to the manufacturer's instructions. Quantitative PCR was then performed using Prime PCR Assays, SsoAdvanced Universal Supermix (Bio-Rad) and $10 \mathrm{ng}$ of template cDNA. PCR reactions were run on a MiniOpticon real-time PCR 

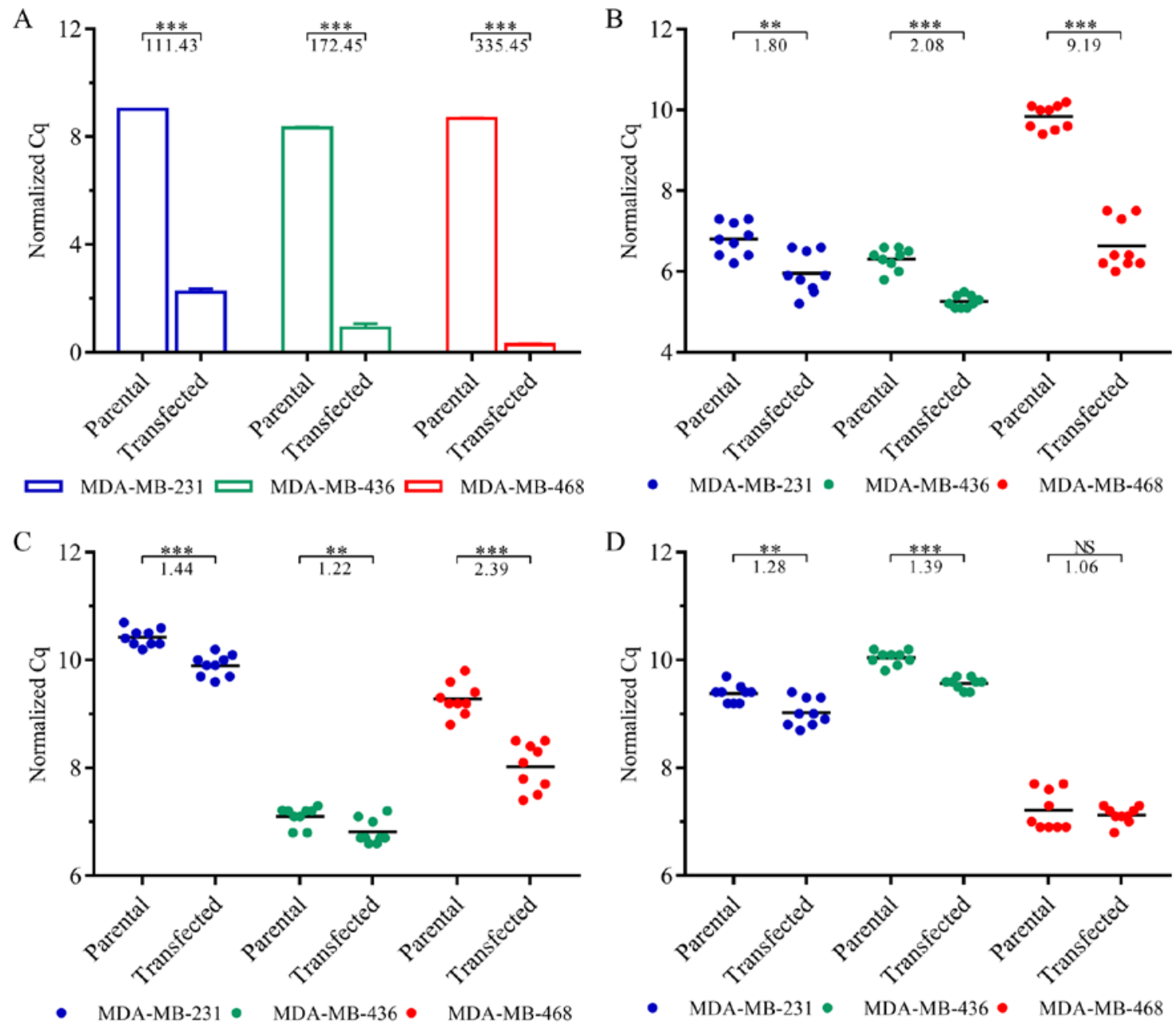

Figure 1. Validation of $\mathrm{NR} 3 \mathrm{Cl}$ overexpression. (A) Transfection with $\mathrm{NR} 3 \mathrm{Cl}$-coding plasmids significantly increased glucocorticoid receptor (GR) expression in the MDA-MB-231, MDA-MB-436 and MDA-MB-468 cells. Analysis of GR downstream effectors (B) DUSP1, (C) SGK1 and (D) GILZ, DUSP and SGK1 were significantly upregulated in all GR-overexpressing TNBC cell lines, while the expression levels of GILZ were not altered significantly in the transfected MDA-MB-468 cells. Numbers below significance indicator display corresponding fold change. ${ }^{* * *} \mathrm{P}<0.01 ;{ }^{* * * *} \mathrm{P}<0.001$; NS, not significant; FC, fold change.

system (Bio-Rad). Target gene Cq values were normalized to GAPDH (19).

\section{Results}

Plasmid transfection induces the expression of NR3Cl and downstream effectors. The transfection of the TNBC cells with NR3C1-coding plasmids was validated by RT-qPCR (Fig. 1A). GR expression was significantly increased in the transfected MDA-MB-231 (111-fold, P=1.75E-4), MDA-MB-436 (172-fold, $\mathrm{P}=2.51 \mathrm{E}-4$ ) and MDA-MB-468 (335-fold, $\mathrm{P}=6.39 \mathrm{E}-6$ ) cells .

To assess overexpression-induced changes in GR signaling, we additionally quantified the expression levels of GR target genes DUSPI (Fig. 1B), SGK1 (Fig. 1C) and GILZ (Fig. 1D). While DUSPI and $S G K 1$ were significantly upregulated in all cell lines, GILZ expression was not altered significantly in the MDA-MB-468 cells $(\mathrm{P}=0.51)$. In the MDA-MB-231 and MDA-MB-436 cells, however, GILZ expression was significantly increased $(\mathrm{P}=2.79 \mathrm{E}-3$ and $\mathrm{P}=3.79 \mathrm{E}-7$, respectively).

TNBC secretes extracellular vesicles carrying RNA. EVs isolated from the conditioned media of the parental MDA-MB-231 and MDA-MB-468 cells were characterized by

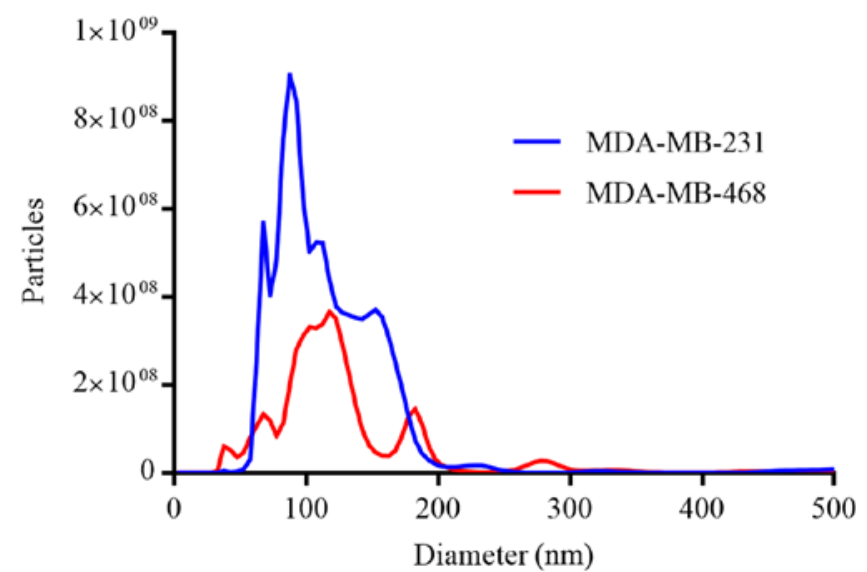

Figure 2. Particle size distribution in extracellular vesicle (EV) preparations from MDA-MB-231 and MDA-MB-468 cells. The area under the curve represents the absolute number of particles isolated from $7.5 \mathrm{ml}$ conditioned media.

NTA (Fig. 2). Single-particle analysis revealed a narrow size distribution with mean particle diameters of $119.0 \pm 74.4 \mathrm{~nm}$ (mode, $87.5 \mathrm{~nm}$ ) and $140.0 \pm 116.7 \mathrm{~nm}$ (mode, $117.5 \mathrm{~nm}$ ) for the MDA-MB-231 and MDA-MB-468 cells, respectively. Despite 

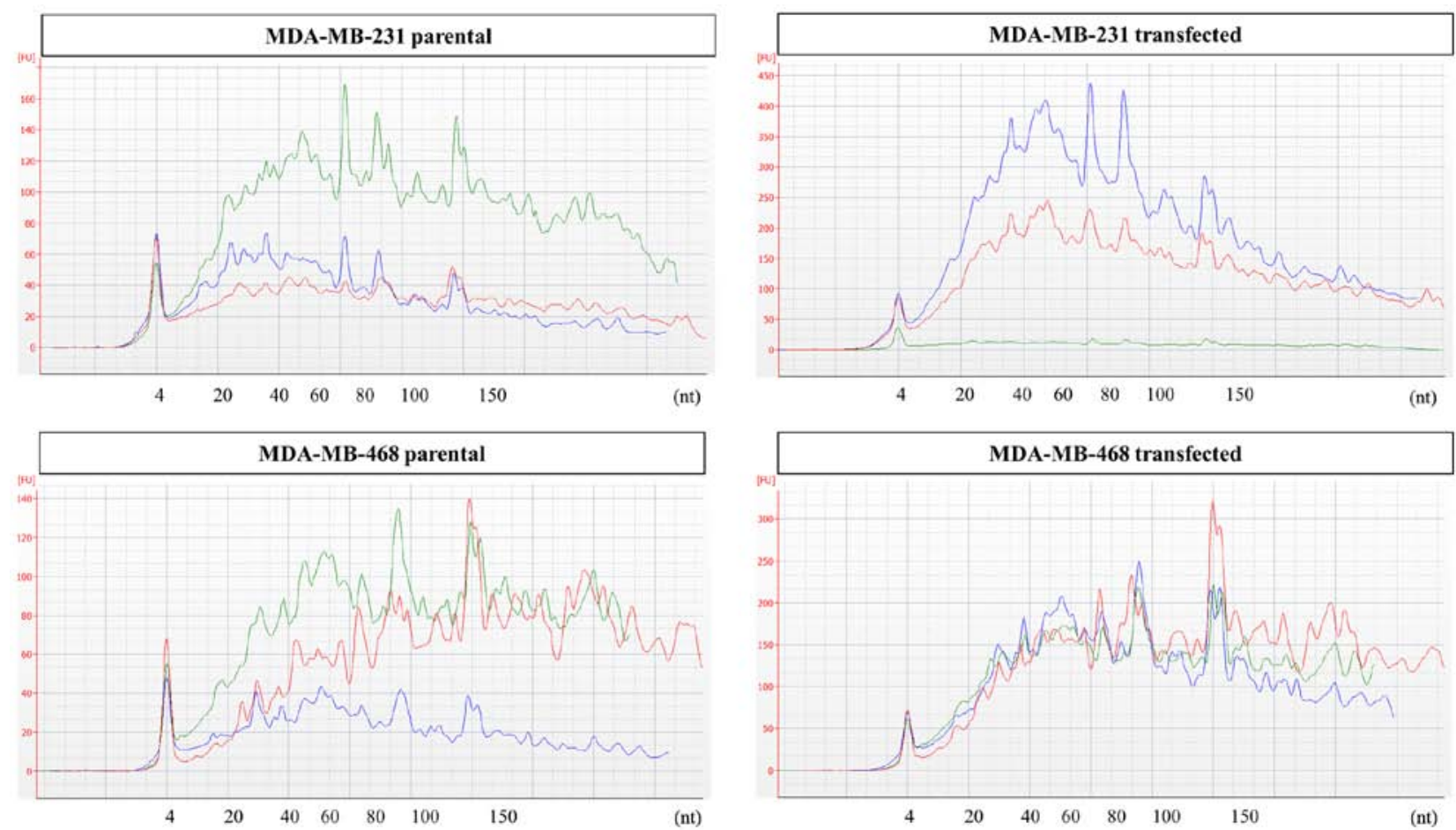

Figure 3. Bioanalyzer electropherograms for small RNA analysis in extracellular vesicles (EVs) from parental (left panels) and transfected (right panels) of MDA-MB-231 and MDA-MB-468 cells. FU, fluorescence unit; nt, nucleotide.

Table II. Library sizes and number of detected miRNA species in MDA-MB-231 and MDA-MB-468 EVs.

\begin{tabular}{lcc}
\hline & \multicolumn{2}{c}{ MDA-MB-231 cells } \\
\cline { 2 - 3 } & Parental & Transfected \\
\hline Library size \pm SD & $1.11 \mathrm{E} 7 \pm 1.66 \mathrm{E} 6$ & $1.27 \mathrm{E} 7 \pm 1.64 \mathrm{E} 6$ \\
Distinct miRNAs & 796 & 788 \\
\hline & \multicolumn{2}{c}{ MDA-MB-468 cells } \\
\cline { 2 - 3 } & Parental & Transfected \\
\hline Library size \pm SD & $1.09 \mathrm{E} 7 \pm 1.25 \mathrm{E} 6$ & $1.25 \mathrm{E} 7 \pm 1.50 \mathrm{E} 6$ \\
Distinct miRNAs & 762 & 736 \\
\hline
\end{tabular}

EV, extracellular vesicle; SD, standard deviation.

the similarities in diameter, significantly more particles were isolated from the MDA-MB-231 cells $(\mathrm{P}<0.001)$.

Prior to sequencing, RNA extracted from EV preparations was analyzed by capillary electrophoresis. Samples from both cell lines were found to be enriched in small RNA species $<150 \mathrm{nt}$ without obvious differences in size profiles between the parental and transfected cells. Full electropherograms for small RNA analysis are provided in Fig. 3.

GR overexpression does not alter vesicular miRNA profiles. EV RNA from the MDA-MB-231 and MDA-MB-468 cells was profiled by small RNA-Seq. The mean per-replicate library sizes are provided in Table II. After mapping to

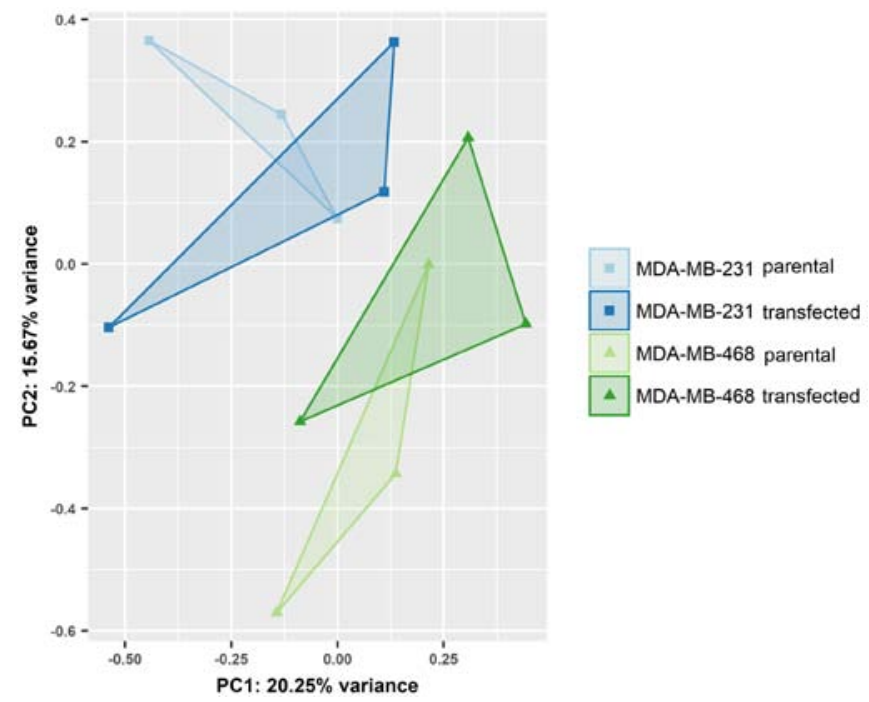

Figure 4. Principal component analysis of miRNA expression in MDA-MB-231 and MDA-MB-468 extracellular vesicles (EVs). Even though the cell lines were clearly separated, expression patterns in EVs from parental and transfected cells overlapped.

miRBase, between 736 (MDA-MB-468, transfected) and 796 (MDA-MB-231, parental) distinct miRNA transcripts were detected in at least one sample. For EVs from both cell lines, there was significant overlap in the 10 most highly expressed miRNAs between the treatment groups (Table III).

Differential expression of miRNAs was assessed in EVs from the parental and transfected MDA-MB-231 and MDA-MB-468 cells. While individual cell lines were clearly distinguished by principal component analysis (Fig. 4), the overexpression of GR did not lead to noticeable changes in 
Table III. Top 10 most highly expressed miRNAs in EVs from parental and transfected MDA-MB-231 and MDA-MB-468 EVs.

\begin{tabular}{lccc}
\hline & MDA-MB-231 parental & & \multicolumn{2}{c}{ MDA-MB-231 transfected } \\
\cline { 1 - 2 } miRNA & Count \pm SD & Count \pm SD \\
\hline miR-100-5p & $32,896.06 \pm 15,567.28$ & miR-100-5p & $28,093.64 \pm 1,746.75$ \\
miR-21-5p & $20,517.88 \pm 6,132.81$ & miR-21-5p & $20,563.67 \pm 13,352.19$ \\
let-7f-5p & $14,534.16 \pm 7,389.27$ & let-7i-5p & $16,700.98 \pm 7,018.44$ \\
let-7i-5p & $13,851.26 \pm 3,041.99$ & let-7f-5p & $13,224.79 \pm 6,215.57$ \\
miR-486-5p & $12,773.16 \pm 9,474.51$ & let-7a-5p & $13,170.83 \pm 7,480.14$ \\
let-7a-5p & $12,044.75 \pm 4,144.34$ & miR-486-5p & $12,251.12 \pm 9,557.67$ \\
miR-92a-3p & $9,763.94 \pm 5,940.53$ & miR-451a & $11,594.65 \pm 13,346.77$ \\
let-7g-5p & $9,167.48 \pm 3,312.17$ & let-7g-5p & $9,583.62 \pm 3,853.93$ \\
miR-451a & $8,899.87 \pm 5,035.93$ & miR-92a-3p & $8,909.74 \pm 4,096.12$ \\
miR-27b-3p & $7,298.91 \pm 2,952.47$ & miR-27b-3p & $7,004.21 \pm 4,888.94$ \\
\hline
\end{tabular}

MDA-MB-468 parental

\begin{tabular}{lccc}
\hline miRNA & Count \pm SD & & miRNA \\
let-7f-2-3p & $20,174.15 \pm 3,134.83$ & miR-505-3p & $17,483.16 \pm 12,287.71$ \\
miR-103b & $14,956.91 \pm 4,896.68$ & miR-4742-3p & $15,703.77 \pm 5,227.01$ \\
miR-4742-3p & $14,411.10 \pm 5,455.42$ & miR-103b & $14,095.48 \pm 11,598.41$ \\
let-7a-3p & $13,768.25 \pm 2,884.00$ & let-7f-2-3p & $13,819.32 \pm 4,499.01$ \\
miR-505-3p & $10,494.01 \pm 2,170.28$ & let-7a-3p & $9,814.04 \pm 2,947.26$ \\
let-7f-5p & $10,065.30 \pm 2,199.66$ & let-7i-3p & $8,987.19 \pm 3,015.38$ \\
let-7i-3p & $9,369.82 \pm 1,379.22$ & let-7f-5p & $8,452.97 \pm 2,966.55$ \\
miR-22-5p & $7,455.85 \pm 526.85$ & miR-22-5p & $7,692.73 \pm 2,962.41$ \\
let-7b-3p & $5,176.99 \pm 1,522.35$ & miR-196b-5p & $4,445.60 \pm 5,386.47$ \\
miR-196b-5p & $3,375.73 \pm 1,780.00$ & miR-27b-3p & $3,582.84 \pm 1,131.12$ \\
\hline
\end{tabular}

Data are mean normalized readcounts for 3 replicates each. EV, extracellular vesicle; SD, standard deviation.

Table IV. Library sizes and number of detected miRNA species in MDA-MB-231, MDA-MB-436 and MDA-MB-468 cells.

\begin{tabular}{lcc}
\hline & \multicolumn{2}{c}{ MDA-MB-231 cells } \\
\cline { 2 - 3 } & Parental & Transfected \\
\hline Library size \pm SD & $9.42 \mathrm{E} 61.56 \mathrm{E} 6$ & $\begin{array}{c}7.98 \mathrm{E} 6 \pm 8.10 \mathrm{E} 5 \\
\text { Distinct miRNAs }\end{array}$ \\
\hline & \multicolumn{2}{c}{ MDA-MB-436 cells } \\
\cline { 2 - 3 } & Parental & Transfected \\
\hline Library size \pm SD & $9.25 \mathrm{E} 6 \pm 8.75 \mathrm{E} 5$ & $8.28 \mathrm{E} 6 \pm 5.92 \mathrm{E} 5$ \\
Distinct miRNAs & 1,187 & 1,216 \\
\hline & \multicolumn{2}{c}{ MDA-MB-468 cells } \\
\cline { 2 - 3 } & Parental & Transfected \\
\hline Library size \pm SD & $8.32 \mathrm{E} 6 \pm 1.23 \mathrm{E} 6$ & $\begin{array}{c}7.27 \mathrm{E} 6 \pm 9.70 \mathrm{E} 5 \\
1,016\end{array}$ \\
\hline
\end{tabular}

$\mathrm{SD}$, standard deviation.
miRNA expression. None of the miRNAs detected in small RNA-Seq displayed statistically significant regulation between endogenous and artificially induced GR expression.

Changes in cellular RNA profiles upon GR overexpression. Cellular RNA was initially analyzed by capillary electrophoresis to assess its suitability for NGS analysis. For all cell lines, samples from both parental and transfected cells featured excellent RNA integrity, as indicated by the RNA integrity number $($ RIN) values $>9$. Bioanalyzer electropherograms for cellular RNA are shown in Fig. 5.

In the NGS data, both the mean size of sequencing libraries and the number of detected miRNAs were higher than in the EV samples (Table IV compared with Table II). The most highly expressed miRNAs in all of the three parental cell lines displayed a high degree of similarity, sharing 8 of the top 10 miRNAs (Table V). Similarly, 7 of the top 10 most highly expressed miRNAs were common to all transfected cell lines.

Differential gene expression analysis revealed slight, yet statistically significant changes in specific miRNAs during GR overexpression (Table VI). Of note, a different set of GR-responsive miRNAs was detected in each of the TNBC cell lines studied herein, highlighting the heterogeneity of molecular signaling. As shown in Fig. 6, miRNA expression 

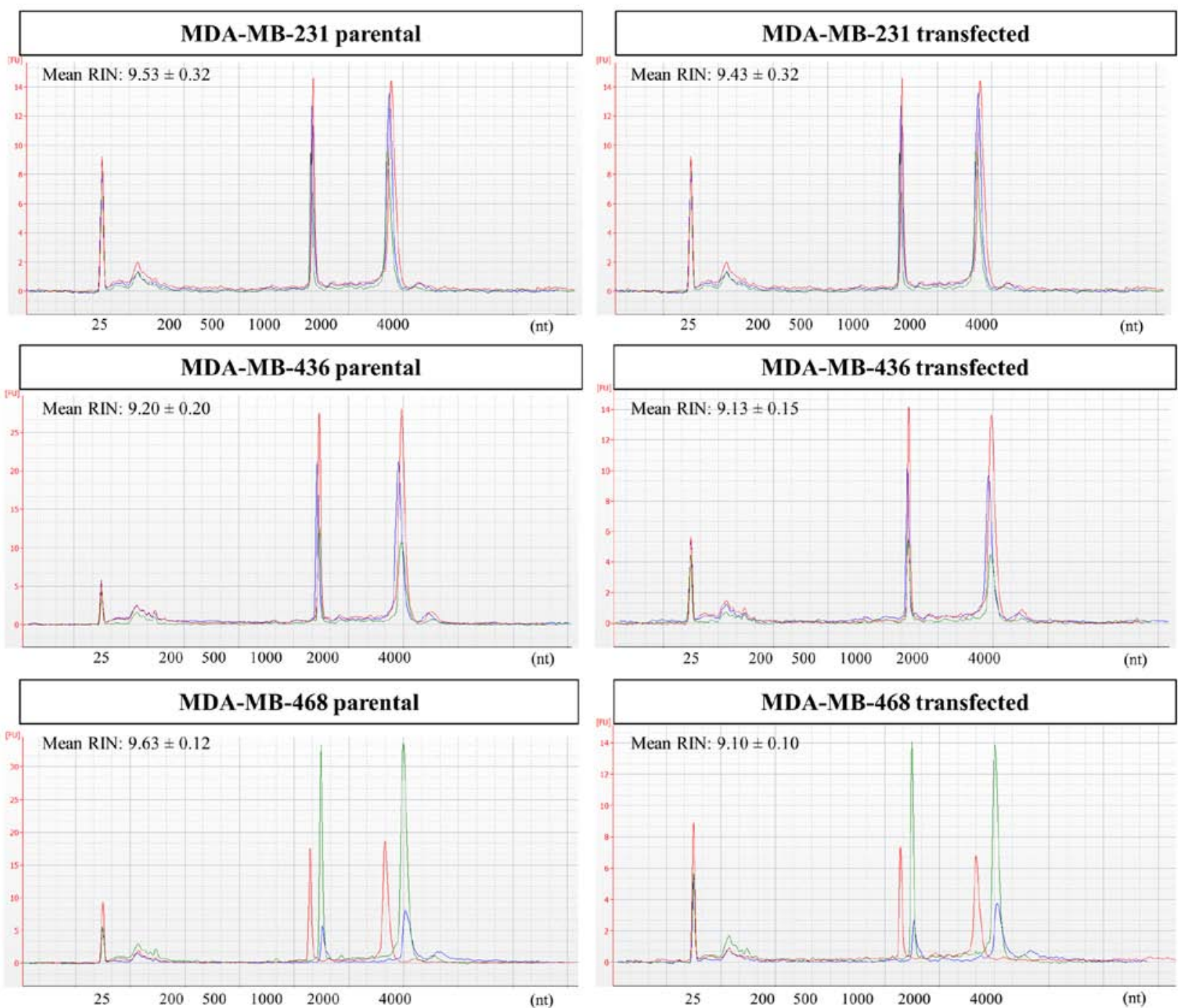

Figure 5. Bioanalyzer electropherograms for total RNA analysis in parental (left panels) and transfected (right panels) MDA-MB-231, MDA-MB-436 and MDA-MB-468 cells. RIN, RNA integrity number; FU, fluorescence unit; nt, nucleotide.

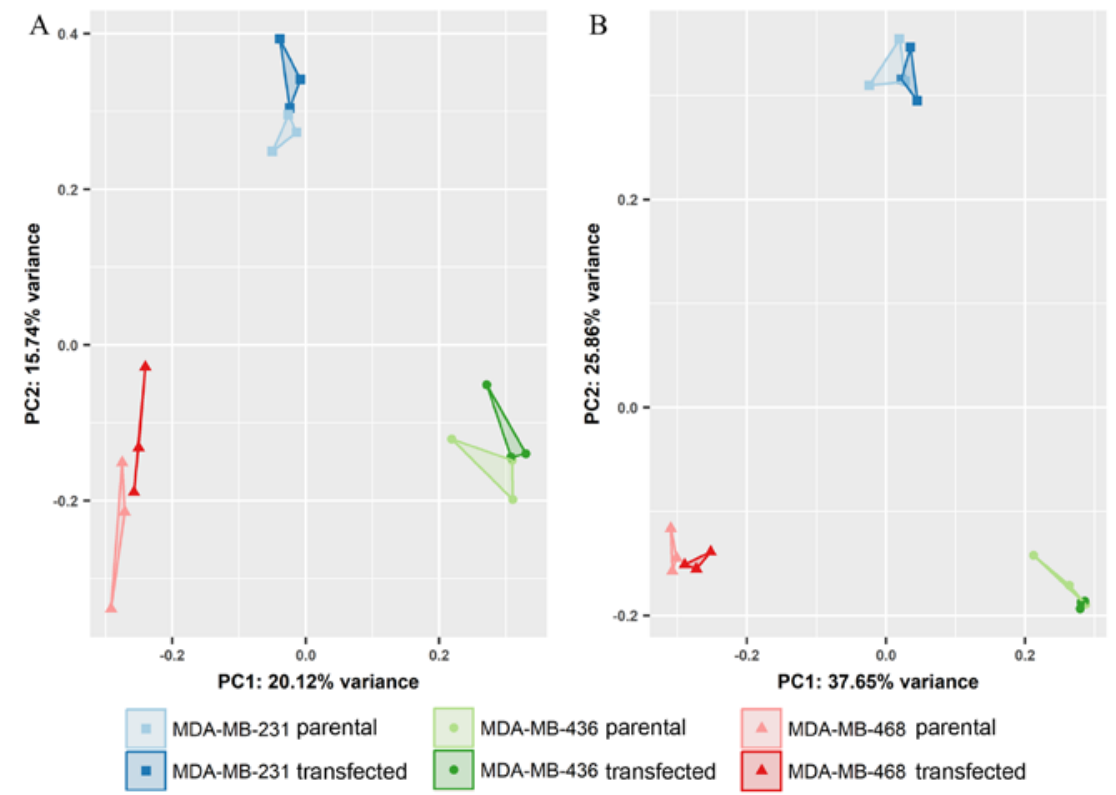

Figure 6. Principal component analysis of intracellular miRNA expression. (A) Based on all miRNAs, individual cell lines were clearly separated on principal components 1 and 2 with subtle differences between parental and transfected cells. (B) Analysis of the top 500 highest variance miRNAs reduced the separation of groups. 
Table V. Top 10 most highly expressed miRNAs in parental and transfected MDA-MB-231, MDA-MB-436 and MDA-MB-468 cells.

\begin{tabular}{|c|c|c|c|}
\hline \multicolumn{2}{|c|}{ MDA-MB-231 parental } & \multicolumn{2}{|c|}{ MDA-MB-231 transfected } \\
\hline miRNA & Count \pm SD & miRNA & Count \pm SD \\
\hline miR-100-5p & $963,722.05 \pm 111,405.87$ & miR-100-5p & $1,348,718.94 \pm 345,916.54$ \\
\hline let-7i-5p & $663,458.05 \pm 68,993.69$ & let-7i-5p & $774,622.60 \pm 97,337.13$ \\
\hline let-7f-5p & $267,434.97 \pm 31,684.39$ & let $-7 f-5 p$ & $324,183.97 \pm 17,197.04$ \\
\hline let-7a-5p & $195,527.39 \pm 12,006.56$ & let-7a-5p & $204,938.44 \pm 20,414.46$ \\
\hline $\operatorname{miR}-151 a-3 p$ & $106,021.75 \pm 1 a ̊ 1,082.05$ & miR-151a-3p & $163,277.67 \pm 56,462.79$ \\
\hline let-7g-5p & $90,178.84 \pm 13,127.37$ & miR-21-5p & $80,090.23 \pm 21,445.21$ \\
\hline miR-21-5p & $67,628.11 \pm 16,283.91$ & let-7g-5p & $78,292.35 \pm 25,760.59$ \\
\hline $\operatorname{miR}-92 a-3 p$ & $57,221.86 \pm 7,227.13$ & $\operatorname{miR}-92 a-3 p$ & $61,589.95 \pm 11,515.77$ \\
\hline miR-99b-5p & $51,137.53 \pm 9,440.27$ & $\operatorname{miR}-10 a-5 p$ & $60,968.56 \pm 16,758.93$ \\
\hline $\operatorname{miR}-26 a-5 p$ & $46,946.37 \pm 4,194.59$ & miR-99b-5p & $57,331.95 \pm 10,509.88$ \\
\hline \multicolumn{2}{|c|}{ MDA-MB-436 parental } & \multicolumn{2}{|c|}{ MDA-MB-436 transfected } \\
\hline miRNA & Count \pm SD & miRNA & Count \pm SD \\
\hline let-7f-5p & $374,536.91 \pm 26,561.27$ & let-7f-5p & $340,698.27 \pm 40,869.66$ \\
\hline $\operatorname{miR}-148 a-3 p$ & $184,192.97 \pm 10,352.18$ & $\operatorname{miR}-148 a-3 p$ & $226,502.28 \pm 169,068.63$ \\
\hline let-7a-5p & $153,782.25 \pm 10,424.01$ & let-7a-5p & $163,998.51 \pm 24,567.84$ \\
\hline let-7i-5p & $146,573.76 \pm 5,731.89$ & let-7i-5p & $157,923.40 \pm 59,299.50$ \\
\hline $\operatorname{miR}-92 a-3 p$ & $138,702.18 \pm 11,122.50$ & miR-151a-3p & $148,161.03 \pm 108,764.69$ \\
\hline $\operatorname{miR}-151 a-3 p$ & $123,436.41 \pm 9,688.08$ & miR-92a-3p & $116,819.87 \pm 14,412.48$ \\
\hline $\operatorname{miR}-100-5 p$ & $71,942.27 \pm 10,410.65$ & $\operatorname{miR}-100-5 p$ & $74,514.77 \pm 19,201.37$ \\
\hline let- $7 g-5 p$ & $71,876.07 \pm 1,749.76$ & miR-21-5p & $66,313.38 \pm 31,125.38$ \\
\hline $\operatorname{miR}-21-5 p$ & $55,083.27 \pm 6,735.91$ & let-7g-5p & $62,873.25 \pm 0,847.78$ \\
\hline miR-99b-5p & $38,293.24 \pm 5,041.04$ & $\operatorname{miR}-27 a-3 p$ & $46,550.47 \pm 14,720.23$ \\
\hline \multicolumn{2}{|c|}{ MDA-MB-468 parental } & \multicolumn{2}{|c|}{ MDA-MB-468 transfected } \\
\hline miRNA & Count \pm SD & miRNA & Count $\pm \mathrm{SD}$ \\
\hline let-7f-5p & $265,322.95 \pm 28,671.87$ & let-7f-5p & $284,627.19 \pm 31,730.98$ \\
\hline let-7i-5p & $235,059.66 \pm 20,017.95$ & let-7i-5p & $187,056.07 \pm 30,924.33$ \\
\hline let-7a-5p & $92,998.25 \pm 9,551.52$ & let-7a-5p & $92,984.74 \pm 14,147.88$ \\
\hline miR-99b-5p & $78,640.71 \pm 22,892.91$ & miR-92a-3p & $85,018.48 \pm 14,067.98$ \\
\hline miR-92a-3p & $75,727.64 \pm 7,097.75$ & miR-99b-5p & $64,627.71 \pm 7,761.79$ \\
\hline $\operatorname{miR}-151 a-3 p$ & $73,088.61 \pm 32,556.30$ & let-7g-5p & $62,517.17 \pm 6,768.50$ \\
\hline let-7g-5p & $50,292.17 \pm 10,045.56$ & miR-21-5p & $49,269.32 \pm 7,542.30$ \\
\hline $\operatorname{miR}-21-5 p$ & $43,287.45 \pm 14,869.30$ & miR-151a-3p & $43,104.23 \pm 13,278.15$ \\
\hline $\operatorname{miR}-25-3 p$ & $38,646.33 \pm 3,045.93$ & $\operatorname{miR}-25-3 p$ & $40,277.41 \pm 1,076.45$ \\
\hline $\operatorname{miR}-30 a-3 p$ & $35,921.06 \pm 9,828.02$ & $\operatorname{miR}-26 a-5 p$ & $33,429.91 \pm 3,036.12$ \\
\hline
\end{tabular}

Data are mean normalized readcounts for three replicates each. SD, standard deviation.

clearly separated individual cell lines, but exhibited only minor differences between the transfected and parental cells. Based on the expression profiles of all miRNAs, principal component 3 (PC3), distinguished parental and GR-overexpressing cells (Fig. 7A). Limiting the input for analysis to the 500 miRNAs with highest variance, however, a reduced separation of groups was observed (Fig. 7B).
We then assessed differential miRNA regulation between endogenous and induced GR expression using RT-qPCR and the Student's t-test. Of the 7 miRNAs found to be significantly regulated in the NGS data, only miR-203a-3p was validated with statistical significance. In the transfected MDA-MB-436 cells, it was upregulated with a $\log 2$ fold change of 0.63 (Fig. 8). 


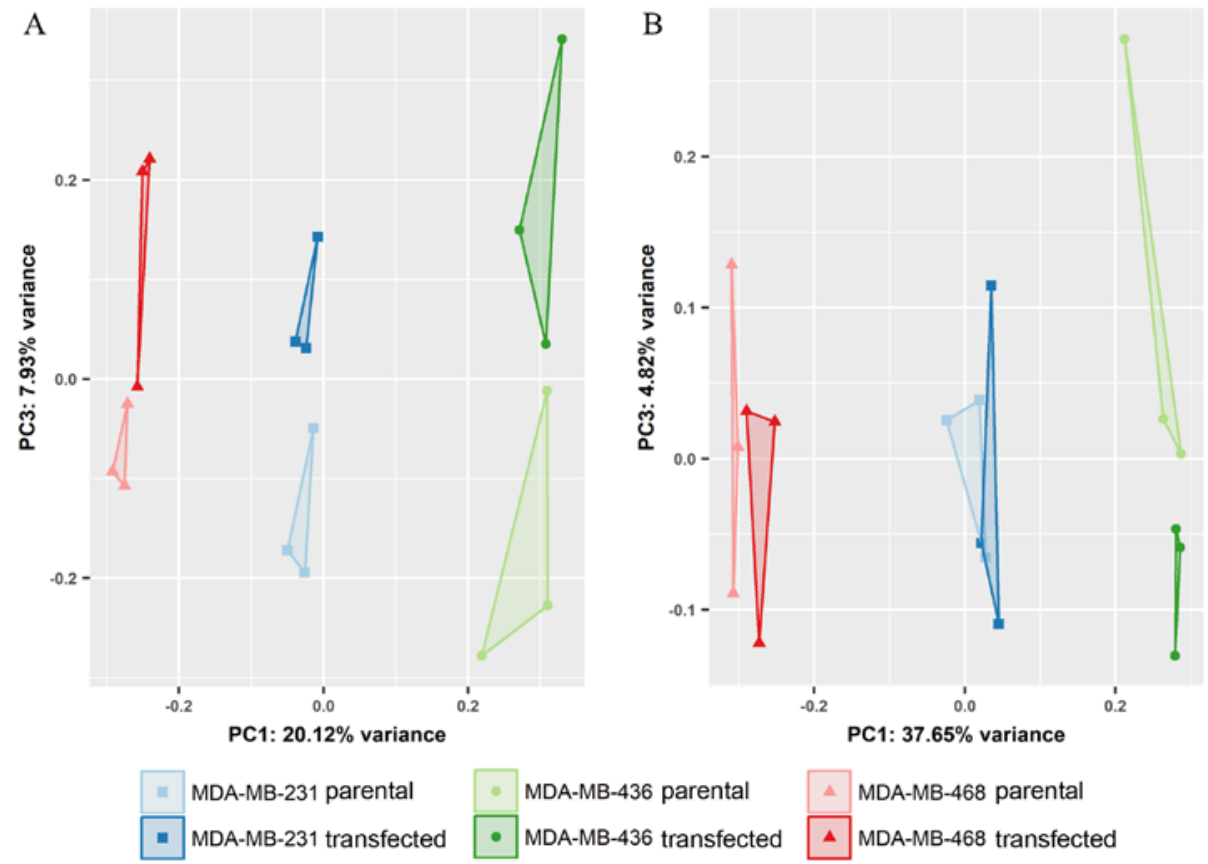

Figure 7. Principal component analysis of intracellular miRNA expression. (A) Analysis of all miRNAs in the dataset separated cell lines (PC1) and treatment groups (PC3). (B) Distances between parental and transfected cells were reduced when limiting the analysis to the top 500 highest variance miRNAs.

Table VI. Cellular miRNAs significantly regulated by GR.

\begin{tabular}{llrrr}
\hline & miRNA & $\log 2 \mathrm{FC}$ & baseMean & P-adj \\
\hline MDA-MB-231 & miR-221-5p & 1.13 & 223.75 & 0.0010 \\
& miR-576-3p & 1.11 & 53.47 & 0.0071 \\
& let-7b-3p & -1.10 & 88.78 & 0.0118 \\
MDA-MB-436 & miR-203a-3p & 1.35 & 134.76 & 0.0301 \\
& miR-4746-5p & -1.07 & 74.25 & 0.0444 \\
MDA-MB-468 & miR-1260a & -1.54 & 291.24 & 0.0003 \\
& miR-1260b & -1.54 & 335.12 & 0.0001
\end{tabular}

Positive fold changes indicate upregulation during GR overexpression. GR, glucocorticoid receptor; $\log 2 \mathrm{FC}, \log 2$ fold change; P-adj, DESeq2-adjusted P-value.

To assess the potential biological functions of miR-203a-3p in the MDA-MB-436 cells, in which it was found to be significantly increased in, we quantified the mRNA levels of 4 of its predicted target genes. Using RT-qPCR, we detected a 3-fold increase in $M Y L K$ expression during GR overexpression $(\mathrm{P}=0.03)$. The expression of ACTG2, CNN1 and HLA-DPB1 was not significantly altered between the parental and transfected cells (data not shown).

\section{Discussion}

TNBC is a particularly aggressive form of BC, leading to a poor prognosis for patients. Both the absence of hormone receptors and its molecular heterogeneity render TNBC a difficult target for therapeutic intervention. Additionally, a high GR expression was recently linked to therapy failure

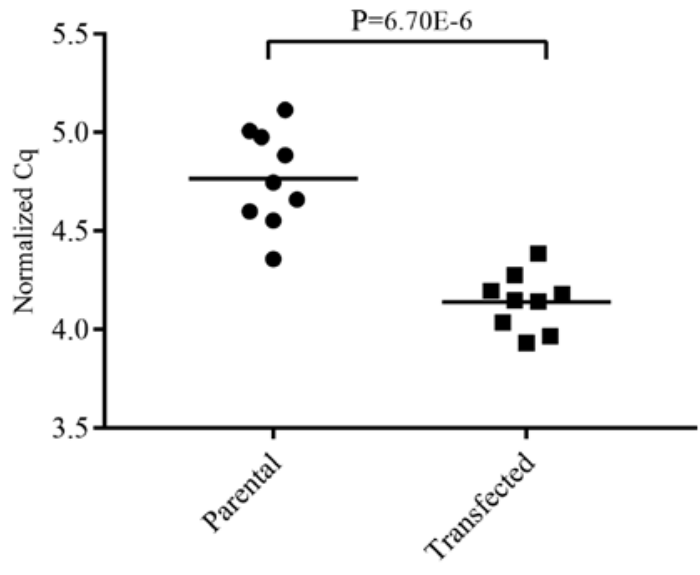

Figure 8. Results from RT-qPCR validation of miR-203a-3p. In transfected MDA-MB-436 cells, miR-203a-3p was upregulated with a $\log 2$ fold change of 0.63 .

and worse outcomes in patients with TNBC, as well as other solid tumors. As Chen et al have previously reported, dexamethasone-mediated GR activation induced the expression of genes involved in carcinogenesis and tumor progression (7). These pro-oncogenic processes may also be fostered by GR-responsive non-coding RNAs, including miRNAs. This study therefore aimed at deciphering potential alterations in extracellular and intracellular miRNAs during GR overexpression.

GR biology is fascinatingly complex, involving liganddependent receptor activation and isoform-specific transcriptional activity $(7,34)$. In this study, we focused on $N R 3 C 1$ transcript variant 1 , as this is not only the most common isoform in epithelial cells, but also more transcriptionally active than others. Additionally, previous studies have demonstrated notable increases in NR3Cl variant 1 in 
TNBC $(35,36)$. As expected, the transfection of TNBC cell lines with $\mathrm{NR} 3 \mathrm{Cl}$-coding plasmids induced both a strong overexpression of GR mRNA and the increased the expression of several downstream targets (37-39). In concordance with previous reports, we found that TNBC cell lines secrete EVs in an exosome-like size range (15-17). Small RNA from cells with endogenous and artificially increased GR expression was sequenced, and miRNAs compared in differential expression analyses. Although a total of 419 and 442 miRNAs were detected in the MDA-MB-231 and MDA-MB-468 EVs, respectively, there were no statistically significant changes in miRNA profiles for either cell line. Increased metastasis and the progression of GR-overexpressing TNBC may therefore not be mediated by the secretion of soluble mediators to a significant extent. On the other hand, Harris et al recently identified vesicular proteins involved in BC metastasis, indicating a signaling function of vesicle components other than miRNAs (15). Circulating miRNAs are, however, not restricted to EVs, but can also be transported by lipoproteins and protein complexes, such as Argonaute2 (Ago2) $(40,41)$. Given that this study focused exclusively on vesicular miRNAs, no conclusions can be drawn about the impact of GR expression on secreted miRNAs associated with other carrier vehicles.

When assessing the impact of GR overexpression on intracellular expression profiles, we detected a slight, cell line-specific modulation of 7 miRNAs. Even though the impact of GR signaling on TNBC miRNAs has not yet been elucidated, previous studies have reported GR-responsive miRNAs in primary lymphocytes, as well as in liver and spleen cells (42-44). In our data, the non-overlapping profiles of regulated miRNAs in the studied cell lines may be reflective of the inherent transcriptional heterogeneity of TNBC phenotypes $(13,45,46)$. Rainer et al reported similar findings for several lymphoma cell lines that, although featuring GR-reactive miRNAs, only displayed moderate and nonuniform changes in miRNA profiles upon GR activation by dexamethasone (47). In our data, the parental and transfected cells were separated by changes in the global expression profile of miRNAs (Fig. 7). Distances between groups decreased when reducing the number of analyzed miRNAs, indicating that GR slightly shifts the expression patterns of many miRNAs, instead of inducing large changes in the abundance of a few specific transcripts.

Of note, miR-203a-3p, upregulated by GR expression in MDA-MB-436 cells, is controversially discussed in BC literature. Several studies have reported its overexpression in $\mathrm{BC}$, as well as an association with a poor prognosis (48-50). Different data, on the other hand, have suggested that miR-203a-3p serves as a tumor suppressor miRNA, and have stated a decreased expression in BC (51-53). In this study, we found miR-203a-3p to be significantly upregulated in the MDA-MB- 436 cells upon the overexpression of GR. As GR is known to be associated with tumor progression, this finding may corroborate the postulation of miR-203a-3p as an oncogenic factor in BC. However, considering the magnitude of expression changes, its biological impact may be of minor relevance. In line with our findings, a previous study reported an upregulation of miR-203 in dexamethasone-treated bone cells, potentially indicating a common miRNA response to GR activation across cell types (54).
The myosin light chain kinase ( $M Y L K, M L C K)$ has been shown to interact with PI3K-AKT and p38 signaling, increasing cell motility and inhibiting apoptosis in BC cells $(55,56)$. Furthermore, Sundararajan et al pointed out the ability of MYLK to promote invasiveness in several BC cell lines (57). Additionally, using LC-MS/MS-based proteomic profiling, Lawrence et al reported TNBC to feature particularly high levels of $M Y L K$ compared to less aggressive BC variants (58). As $M Y L K$ is a predicted miR-203a-3p target, we quantified its expression in MDA-MB-436 levels using RT-qPCR. Surprisingly, an increased miR-203a-3p expression in the transfected cells was accompanied by a 3 -fold increase in MYLK mRNA levels. This finding was not in concordance with our expectations, as canonical miRNA regulation involves binding of mRNAs and repressing their translation. Consequently, the observed upregulation indicates that $M Y L K$ is not directly bound and downregulated by miR-203a-3p.

Taken together, our data suggest that $M Y L K$ may be regulated by GR, and can be regarded as a candidate gene involved in the poor survival rates of TNBC patients overexpressing GR. GR's mode of action on $M Y L K$, however, seems not to be mediated by major alterations in cellular miRNAs.

In conclusion, we did not observe any prominent alterations in cellular or vesicular miRNA profiles upon overexpression of GR. The patterns of miRNA expression seem to be influenced by GR to only a small degree, and other mechanisms may therefore be the primary driver for the higher mortality rates of patients suffering from TNBC with GR overexpression.

\section{Acknowledgements}

The authors wish to thank Franz Jansen for excellent technical assistance. We are grateful to Renate Scheler and Dr Ricarda Schumann from the University Eye Hospital LMU Munich for excellent assistance with TEM. We also wish to thank Professor Jörg Kleiber for kindly providing access to the NanoSight LM10.

\section{Funding}

This study was supported by the K.L. Weigand'sche Stiftung, Curt-Bohnewands-Fonds, Georg and Traud Gravenhorst Stiftung, as well as by the Friedrich-Baur-Stiftung. The funders had no role in the study design, data collection and analysis, decision to publish, or preparation of the manuscript.

\section{Availability of data and materials}

The analyzed datasets generated during the study are available from the corresponding author on reasonable request.

\section{Authors' contributions}

MR, GS and OS conceived and designed the experiments; DB, RG, CM and MR performed the experiments; DB, RG, BK and MR and performed the validation and formal analysis; DB, BK, MWP and MR curated and analyzed the data; DB, BK and MR wrote the manuscript; MWP, GS and OS reviewed and revised the manuscript; MR, OS and GS acquired funding. All authors have read and approved the final manuscript. 


\section{Ethics approval and consent to participate}

Not applicable.

\section{Consent for publication}

Not applicable.

\section{Competing interests}

The authors declare that they have no competing interests.

\section{References}

1. Ataollahi MR, Sharifi J, Paknahad MR and Paknahad A: Breast cancer and associated factors: A review. J Med Life 8: 6-11, 2015

2. Malvezzi M, Bertuccio P, Levi F, La Vecchia C and Negri E: European cancer mortality predictions for the year 2014. Ann Oncol 25: 1650-1656, 2014

3. Wahba HA and El-Hadaad HA: Current approaches in treatment of triple-negative breast cancer. Cancer Biol Med 12: 106-116, 2015.

4. Yagata H, Kajiura Y and Yamauchi H: Current strategy for triplenegative breast cancer: Appropriate combination of surgery, radiation, and chemotherapy. Breast Cancer 18: 165-173, 2011.

5. Hurvitz S and Mead M: Triple-negative breast cancer: Advancements in characterization and treatment approach. Curr Opin Obstet Gynecol 28: 59-69, 2016.

6. Sundahl N, Clarisse D, Bracke M, Offner F, Berghe WV and Beck IM: Selective glucocorticoid receptor-activating adjuvant therapy in cancer treatments. Oncoscience 3: 188-202, 2016.

7. Chen Z, Lan X, Wu D, Sunkel B, Ye Z, Huang J, Liu Z, Clinton SK, Jin VX and Wang Q: Ligand-dependent genomic function of glucocorticoid receptor in triple-negative breast cancer. Nat Commun 6: 8323, 2015.

8. Skor MN, Wonder EL, Kocherginsky M, Goyal A, Hall BA, Cai Y and Conzen SD: Glucocorticoid receptor antagonism as a novel therapy for triple-negative breast cancer. Clin Cancer Res 19: 6163-6172, 2013

9. Tessel MA, Krett NL and Rosen ST: Steroid receptor and microRNA regulation in cancer. Curr Opin Oncol 22: 592-597, 2010.

10. Zhang B, Pan X, Cobb GP and Anderson TA: microRNAs as oncogenes and tumor suppressors. Dev Biol 302: 1-12, 2007.

11. Lowery AJ, Miller N, Devaney A, McNeill RE, Davoren PA, Lemetre C, Benes V, Schmidt S, Blake J, Ball G, et al: MicroRNA signatures predict oestrogen receptor, progesterone receptor and HER2/neu receptor status in breast cancer. Breast Cancer Res 11: R27, 2009.

12. Chang YY, Kuo WH, Hung JH, Lee CY, Lee YH, Chang YC, Lin WC, Shen CY, Huang CS, Hsieh FJ, et al: Deregulated microRNAs in triple-negative breast cancer revealed by deep sequencing. Mol Cancer 14: 36, 2015.

13. Cascione L, Gasparini P, Lovat F, Carasi S, Pulvirenti A, Ferro A, Alder $\mathrm{H}, \mathrm{He} \mathrm{G}$, Vecchione A, Croce CM, et al: Integrated microRNA and mRNA signatures associated with survival in triple negative breast cancer. PLoS One 8: e55910, 2013

14. Falcone G, Felsani A and D'Agnano I: Signaling by exosomal microRNAs in cancer. J Exp Clin Cancer Res 34: 32, 2015.

15. Harris DA, Patel SH, Gucek M, Hendrix A, Westbroek W and Taraska JW: Exosomes released from breast cancer carcinomas stimulate cell movement. PLoS One 10: e0117495, 2015.

16. O'Brien K, Rani S, Corcoran C, Wallace R, Hughes L, Friel AM, McDonnell S, Crown J, Radomski MW and O'Driscoll L: Exosomes from triple-negative breast cancer cells can transfer phenotypic traits representing their cells of origin to secondary cells. Eur J Cancer 49: 1845-1859, 2013.

17. Singh R, Pochampally R, Watabe K, Lu Z and Mo YY: Exosomemediated transfer of miR-10b promotes cell invasion in breast cancer. Mol Cancer 13: 256, 2014

18. Liu Y, Zhang Y, Li Q, Li J, Ma X, Xing J, Rong S, Wu Z, Tian Y, Li J, et al: MiRNAs predict the prognosis of patients with triple negative breast cancer: A meta-analysis. PLoS One 12: e0170088, 2017.
19. Liu LL, Zhao H, Ma TF, Ge F, Chen CS and Zhang YP: Identification of valid reference genes for the normalization of RT-qPCR expression studies in human breast cancer cell lines treated with and without transient transfection. PLoS One 10: e0117058, 2015.

20. Livak KJ and Schmittgen TD: Analysis of relative gene expression data using real-time quantitative PCR and the 2(-Delta Delta C(T)) Method. Methods 25: 402-408, 2001.

21. Spornraft M, Kirchner B, Haase B, Benes V, Pfaffl MW and Riedmaier I: Optimization of extraction of circulating RNAs from plasma - enabling small RNA sequencing. PLoS One 9: e107259, 2014

22. Andrews S: FastQC: a quality control tool for high throughput sequence data. http://www.citeulike.org/user/nailest/article/ 11583827. Accessed Nov 21, 2017.

23. Kong Y: Btrim: A fast, lightweight adapter and quality trimming program for next-generation sequencing technologies. Genomics 98: 152-153, 2011.

24. Buschmann D, Haberberger A, Kirchner B, Spornraft M, Riedmaier I, Schelling G and Pfaffl MW: Toward reliable biomarker signatures in the age of liquid biopsies - how to standardize the small RNA-Seq workflow. Nucleic Acids Res 44: 5995-6018, 2016.

25. Consortium RN; RNAcentral Consortium: RNAcentral: An international database of ncRNA sequences. Nucleic Acids Res 43D: D123-D129, 2015

26. Kozomara A and Griffiths-Jones S: miRBase: Annotating high confidence microRNAs using deep sequencing data. Nucleic Acids Res 42 (D1): D68-D73, 2014.

27. Langmead B, Trapnell C, Pop M and Salzberg SL: Ultrafast and memory-efficient alignment of short DNA sequences to the human genome. Genome Biol 10: R25, 2009.

28. Li H, Handsaker B, Wysoker A, Fennell T, Ruan J, Homer N, Marth G, Abecasis G and Durbin R; 1000 Genome Project Data Processing Subgroup: The Sequence Alignment/Map format and SAMtools. Bioinformatics 25: 2078-2079, 2009.

29. Love MI, Huber W and Anders S: Moderated estimation of fold change and dispersion for RNA-seq data with DESeq2. Genome Biol 15: 550, 2014.

30. Vandesompele J, Kubista M and Pfaffl MW: Reference gene validation software for improved normalization. In: Real-Time PCR: Current Technology and Applications. Logan J, Edwards K and Saunders N (eds). Caister Academic Press, London, pp47-64, 2009.

31. Andersen CL, Jensen JL and Ørntoft TF: Normalization of real-time quantitative reverse transcription-PCR data: A modelbased variance estimation approach to identify genes suited for normalization, applied to bladder and colon cancer data sets. Cancer Res 64: 5245-5250, 2004.

32. Dweep H, Sticht C, Pandey P and Gretz N: miRWalk - database: Prediction of possible miRNA binding sites by 'walking' the genes of three genomes. J Biomed Inform 44: 839-847, 2011.

33. Ramaswamy S, Ross KN, Lander ES and Golub TR: A molecular signature of metastasis in primary solid tumors. Nat Genet 33: 49-54, 2003.

34. Lu NZ and Cidlowski JA: Glucocorticoid receptor isoforms generate transcription specificity. Trends Cell Biol 16: 301-307, 2006.

35. Reeder A, Attar M, Nazario L, Bathula C, Zhang A, Hochbaum D, Roy E, Cooper KL, Oesterreich S, Davidson NE, et al: Stress hormones reduce the efficacy of paclitaxel in triple negative breast cancer through induction of DNA damage. Br J Cancer 112: 1461-1470, 2015.

36. McNamara KM, Kannai A and Sasano H: Possible roles for glucocorticoid signalling in breast cancer. Mol Cell Endocrinol S0303-7207(17)30358-1, 2017.

37. Wu W, Pew T, Zou M, Pang D and Conzen SD: Glucocorticoid receptor-induced MAPK phosphatase-1 (MPK-1) expression inhibits paclitaxel-associated MAPK activation and contributes to breast cancer cell survival. J Biol Chem 280: 4117-4124, 2005.

38. Maiyar AC, Phu PT, Huang AJ and Firestone GL: Repression of glucocorticoid receptor transactivation and DNA binding of a glucocorticoid response element within the serum/glucocorticoid-inducible protein kinase (sgk) gene promoter by the p53 tumor suppressor protein. Mol Endocrinol 11: 312-329, 1997.

39. Ayroldi E and Riccardi C: Glucocorticoid-induced leucine zipper (GILZ): A new important mediator of glucocorticoid action. FASEB J 23: 3649-3658, 2009.

40. Arroyo JD, Chevillet JR, Kroh EM, Ruf IK, Pritchard CC, Gibson DF, Mitchell PS, Bennett CF, Pogosova-Agadjanyan EL, Stirewalt DL, et al: Argonaute2 complexes carry a population of circulating microRNAs independent of vesicles in human plasma. Proc Natl Acad Sci USA 108: 5003-5008, 2011. 
41. Vickers KC, Palmisano BT, Shoucri BM, Shamburek RD and Remaley AT: MicroRNAs are transported in plasma and delivered to recipient cells by high-density lipoproteins. Nat Cell Biol 13: 423-433, 2011.

42. Puimège L, Van Hauwermeiren F, Steeland S, Van Ryckeghem S, Vandewalle J, Lodens S, Dejager L, Vandevyver S, Staelens J, Timmermans S, et al: Glucocorticoid-induced microRNA-511 protects against TNF by down-regulating TNFR1. EMBO Mol Med 7: 1004-1017, 2015.

43. Smith LK, Tandon A, Shah RR, Mav D, Scoltock AB and Cidlowski JA: Deep sequencing identification of novel glucocorticoid-responsive miRNAs in apoptotic primary lymphocytes. PLoS One 8: e78316, 2013.

44. Wang ZH, Liang YB, Tang H, Chen ZB, Li ZY, Hu XC and Ma ZF: Dexamethasone down-regulates the expression of microRNA-155 in the livers of septic mice. PLoS One 8: e80547, 2013.

45. Mathe A, Scott RJ and Avery-Kiejda KA: MiRNAs and other epigenetic changes as biomarkers in triple negative breast cancer. Int J Mol Sci 16: 28347-28376, 2015.

46. Radojicic J,Zaravinos A, Vrekoussis T, Kafousi M, Spandidos DA and Stathopoulos EN: MicroRNA expression analysis in triplenegative (ER, PR and Her2/neu) breast cancer. Cell Cycle 10 507-517, 2011.

47. Rainer J, Ploner C, Jesacher S, Ploner A, Eduardoff M, Mansha M, Wasim M, Panzer-Grümayer R, Trajanoski Z, Niederegger H, et al: Glucocorticoid-regulated microRNAs and mirtrons in acute lymphoblastic leukemia. Leukemia 23: 746-752, 2009.

48. Shao Y, Gu W, Ning Z, Song X, Pei H and Jiang J: Evaluating the prognostic value of microRNA-203 in solid tumors based on a meta-analysis and the Cancer Genome Atlas (TCGA) Datasets. Cell Physiol Biochem 41: 1468-1480, 2017.

49. He S, Zhang G, Dong H, Ma M and Sun Q: miR-203 facilitates tumor growth and metastasis by targeting fibroblast growth factor 2 in breast cancer. Onco Targets Ther 9: 6203-6210, 2016

50. Liang Y, Yang W, Zhu Y and Yuan Y: Prognostic role of microRNA-203 in various carcinomas: Evidence from a metaanalysis involving 13 studies. Springerplus 5: 1538, 2016.
51. Ding X, Park SI, McCauley LK and Wang CY: Signaling between transforming growth factor $\beta$ (TGF- $\beta$ ) and transcription factor SNAI2 represses expression of microRNA miR-203 to promote epithelial-mesenchymal transition and tumor metastasis. J Biol Chem 288: 10241-10253, 2013.

52. Wang C, Zheng X, Shen C and Shi Y: MicroRNA-203 suppresses cell proliferation and migration by targeting BIRC5 and LASP1 in human triple-negative breast cancer cells. J Exp Clin Cancer Res 31: 58, 2012

53. Zhang Z, Zhang B, Li W, Fu L, Fu L, Zhu Z and Dong JT: Epigenetic silencing of miR-203 upregulates SNAI2 and contributes to the invasiveness of malignant breast cancer cells. Genes Cancer 2: 782-791, 2011.

54. Laxman N, Rubin CJ, Mallmin H, Nilsson O, Tellgren-Roth C and Kindmark A: Second generation sequencing of microRNA in human bone cells treated with parathyroid hormone or dexamethasone. Bone 84: 181-188, 2016.

55. Choi C, Kwon J, Lim S and Helfman DM: Integrin $\beta 1$, myosin light chain kinase and myosin IIA are required for activation of PI3K-AKT signaling following MEK inhibition in metastatic triple negative breast cancer. Oncotarget 7: 63466-63487, 2016.

56. Cui WJ, Liu Y, Zhou XL, Wang FZ, Zhang XD and Ye LH: Myosin light chain kinase is responsible for high proliferative ability of breast cancer cells via anti-apoptosis involving p38 pathway. Acta Pharmacol Sin 31: 725-732, 2010.

57. Sundararajan V, Gengenbacher N, Stemmler MP, Kleemann JA, Brabletz T and Brabletz S: The ZEB1/miR-200c feedback loop regulates invasion via actin interacting proteins MYLK and TKS5. Oncotarget 6: 27083-27096, 2015.

58. Lawrence RT, Perez EM, Hernández D, Miller CP, Haas KM, Irie HY, Lee SI, Blau CA and Villén J: The proteomic landscape of triple-negative breast cancer. Cell Reports 11: 630-644, 2015.

This work is licensed under a Creative Commons Attribution-NonCommercial-NoDerivatives 4.0 International (CC BY-NC-ND 4.0) License. 